\title{
O TREINAMENTO E A VIA NEGATIVA NO STUDIO STANISLAVSKI
}

\author{
Carolina Almeida Gomes \\ Mestre pela Universidade Federal do Estado do Rio de Janeiro \\ carolinacaju@hotmail.com \\ Joana Ribeiro da Silva Tavares \\ Prof. Adjunto da Universidade Federal do Estado do Rio de Janeiro \\ joana_ribeirodasilvatavares@yahoo.com.br
}

\section{Resumo}

O presente artigo se propõe a discutir a noção de via negativa forjada por Jerzy Grotowski e suas implicações no treinamento físico para atores. Usaremos como base para análise a experiência de apropriação deste modo de treinamento pela companhia teatral carioca Studio Stanislavski.

Palavras-chave

Via Negativa. Treinamento. Ator.
Keywords

Via Negativa. Training. Actor. 


\section{Introdução}

Jerzy Grotowski divide o seu percurso em quatro fases principais ${ }^{1}$ : o teatro dos espetáculos ou da arte como apresentação; o parateatro ou teatro de participação; o teatro das fontes e a arte como veículo. (GROTOWSKI, 1995 In FLASZEN e POLLASTRELLI, 2007, p. 230) O conceito basilar da via negativa, que iremos discutir nesse artigo, pode ser identificado durante a fase do teatro dos espetáculos, que teve como foco principal "a técnica pessoal e cênica do ator". (GROTOWSKI, 1965 In FLASZEN e POLLASTRELLI, 2007, p.105)

No livro organizado por Pollastrelli e Flaszen (2007), o marco inicial desta fase é delimitado quando Grotowski e Flaszen ${ }^{2}$ assumem o Teatro das 13 Fileiras $^{3}$, em 1959, e o marco final incide na estreia do último espetáculo dirigido por Grotowski, Apocalypsis cum Figuris, em 1969. Esta datação, segundo Motta Lima, é reiterada pelos pesquisadores Marco de Marinis (2004), Zbigniew Osinski (1980) e Jenifer Kumiega (1985). Estes incluem, ainda, uma subdivisão que vai de 1959 a 1962, até o espetáculo Os Antepassados, e de 1962 a 1969, a partir do espetáculo Kordian. Esta subdivisão se dá pela percepção de uma mudança de ênfase no trabalho do ator a partir de 1962, o que denota como esta pesquisa, no percur-

1 Mesmo que haja diferenças nessa divisão entre seus pesquisadores, nos ateremos aqui à separação feita pelo próprio Grotowski.

2 Ludwik Flaszen - Nascido em 1930, na Polônia. Ensaísta, escritor, crítico e tradutor. Foi cofundador e força motriz, ao lado de Grotowski, do Teatro Laboratório, ao longo de toda a sua existência, além de, durante o ano de 1980, ter sido seu diretor artístico.

3 Quando fundado, em 1959, por Grotowski e Flaszen, ainda se chamava Teatro das 13 Fileiras. Em 1962, ainda em Opole, passou a se chamar Teatro Laboratório das 13 Fileiras. Em 1965, a companhia se mudou para a cidade de Wroclaw, onde passou a se chamar apenas Teatro Laboratório. so de Grotowski, transformou-se ao longo dos anos. (MOTTA LIMA, 2012, p. 28)

O termo via negativa aparece no léxico grotowskiano 4 a partir do momento em que suas investigações teatrais visam à técnica pessoal e cênica do ator. (GROTOWSKI, 1971) Ainda que tenha ficado mundialmente conhecido como um encenador que explorou "a natureza do jogo do ator, o fenômeno que o constitui" (BROOK, 2009), esta questão não era a princípio o ponto central de suas pesquisas. Grotowski aproximou-se do teatro, motivado pelo desejo de investigar o humano, mas se debruçou primeiro sobre a construção de uma nova teatralidade e a reforma da cena teatral vigente na época. (FLASZEN e POLASTRELI, 2007)

Ao longo do seu percurso como diretor artístico do Teatro das 13 Fileiras, e posteriormente do Teatro Laboratório, Grotowski percebeu que o trabalho do ator sobre suas questões "psicofísicas" era a matéria-prima fundamental para a realização da criação artística. Nessa investigação sobre a corporeidade do ator, o foco era o confronto com o desconhecido (a própria criação), em detrimento de um acúmulo de técnicas ou saberes. E, aqui, o entendimento da via negativa se configurou como uma chave fundamental, tanto na pesquisa do treinamento físico quanto no trabalho criativo. (GROTOWSKI, 1971) Grotowski (1971) [1965] afirma que no Teatro Laboratório o processo de pesquisa com os atores não era direcionado para a apreensão de várias técnicas, mas, sim, para a erradicação de bloqueios. A esta maneira de conduzir a pesquisa atoral, Grotowski chamou de via negativa.

4 Grotowski, ao longo dos seus anos de pesquisa, forjou uma série de conceitos ligados à sua prática teatral que constituíram um léxico particular. Em Palavras Praticadas (2012), a pesquisadora Tatiana Motta Lima empreende o esforço de aprofundar o estudo da construção desse léxico em tensão com as práticas teatrais de Grotowski. 
Dinah Cesare, em sua dissertação de mestrado, intitulada Pensamento Material: o training como linguagem (2010), esclarece-nos que o conceito ético da via negativa era o "ponto nevrálgico" do trabalho desenvolvido por Grotowski. Esta ética estava vinculada não a uma técnica ou método específicos para o trabaIho do ator, mas a uma necessidade constante de se pôr em risco de desconstruir, desmontar os saberes. Neste sentido, Constantin Stanislavski exerceu uma grande influência sobre Grotowski. Em meio às transformações que o teatro sofreu no século XX, época em que imperava a ideia da imitação no trabalho atoral, Stanislavski propôs ao ator uma investigação acerca do que seria necessário ao desenvolvimento de sua "condição criativa". (RUFFINI, 2004, p. 2)

No texto Resposta a Stanislavski (2001), Grotowski revela que, no início dos seus estudos teatrais, Stanislavski foi uma grande referência para ele: "Achava que ele era a chave que abre todas as portas da criatividade. Queria compreendê-lo melhor do que os outros" (2001, p. 6). Ao longo dos anos, a relação de Grotowski com Stanislavski teve diversos momentos (negação, revolta, compreensão). Todavia, Grotowski (2001) afirma que nunca deixou de ver no mestre russo uma inspiração para as suas pesquisas, ainda que em alguns pontos, suas conclusões fossem divergentes.

Grotowski declara, por exemplo, que ele e Stanislavski chegaram a entendimentos díspares sobre o treinamento do ator. Segundo Grotowski, Stanislavski acreditava em um "treinamento positivo", em que o ator aprende uma série de técnicas necessárias a seu ofício. Apesar de reconhecer a importância deste treinamento no contexto e na prática de Stanislavski, Grotowski avalia que o treinamen- to positivo não poderia alcançar o que escapa ao nível consciente no trabalho atoral. Por este motivo, Grotowski (2001, p. 12) opta pela realização de exercícios que tenham um "caráter negativo". Os exercícios de "caráter negativo" eram "exercícios-obstáculos" que serviam "para descobrir o que não se devia fazer, mas nunca o que e como fazer". Grotowski (2001, p. 12) afirma que "quando os exercícios já eram executados com maestria excessiva, eram modificados ou abandonados".

No texto $O$ diretor como espectador de profissão ${ }^{5}$, Grotowski conta que Charles Duits ${ }^{6}$ se apresentava como um guru ocidental que seria capaz de ensinar as pessoas a levitar. No entanto, o objetivo concreto de Duits era ensinar as pessoas a atravessar a rua, durante o horário de pico. Sobre esta história, Grotowski faz a seguinte consideração:

Hoje, há uma tal ruptura de toda a confiança, um tal sentido de insegurança, que se quer aprender só as coisas consideradas concretas e precisas. Então, se eu digo a uma pessoa: quero ensinar-lhe como caminhar com a perna esquerda de maneira perfeita e eficiente, ela se esforçará, trabalhará comigo, poderá até mesmo obter uma certa transcendência. Mas, só porque pensa em trabalhar sobre o movimento da perna esquerda. (GROTOWSKI, 1984 apud FLASZEN e POLLASTRELLI, 2007, p. 213)

Podemos perceber por esta afirmação que, na visão de Grotowski, o trabalho sobre a experiência do corpo, sobre aquilo que seria concreto, pode levar o indivíduo a experimen-

5 Texto publicado no livro O Teatro Laboratório de Jerzy Grotowski 1959-1969, transcrito a partir de uma conferência proferida por Grotowski em Voltera, em 1984. Foi publicado em 1986, na revista Teatro Festival n.3.

6 Charles Duits (1925-1991) - Escritor francês ligado à corrente surrealista. Tem como destaque, em seus romances, a questão sobrenatural e a relação com o mundo espiritual. 
tar algo que está para além desta concretude. Em Resposta a Stanislavski (2001), ele afirma que o treinamento positivo, por almejar apenas o ensino de algumas técnicas indispensáveis ao ofício do ator, não seria o suficiente para desenvolver sua criatividade.

Para Grotowski, a apreensão e consciência da técnica não consideram o sujeito como um ser integrado, no qual há influências de elementos que o bloqueiam a nível inconsciente, por isso seria necessária uma abordagem negativa do treinamento, o que aqui denominaremos como treinamento negativo. Mas como se daria essa abordagem negativa? Como e por que realizar um treinamento no qual o principal objetivo não é aprender técnicas?

\section{O conceito de via negativa}

A partir do espetáculo o Príncipe Constante $(1965)^{7}$, penúltimo espetáculo dirigido por Grotowski na companhia, o entendimento do ofício do ator tomou outro rumo na prática do Teatro Laboratório. O foco da pesquisa teatral se deslocou da construção de estruturas que servissem como elementos de um espetáculo, para a investigação pessoal do ator. Investigação esta que deveria ser desenvolvida em um

7 Peça do Teatro Laboratório, dirigida por Jerzy Grotowski, com base na reformulação do drama de Calderón de la Barca feita por Juliusz Słowacki. A peça conta a história de Don Fernando, príncipe católico português, que é capturado pelos mouros e se vê obrigado a negar a sua fé. Esta peça ficou mundialmente conhecida pelo desempenho do ator Ryszard Cieślak que fez o papel de Don Fernando. O espetáculo foi apresentado muitas vezes tendo sofrido diversas mudanças no elenco, mas sempre com Ryszard no papel principal. processo de "autopenetração", ou revelação, em prol de um encontro genuíno entre atores e espectadores. Nos textos do encenador, escritos a partir deste momento, o trabalho corporal era visto como uma atividade que poderia auxiliar o ator na expansão dos seus limites:

[...] o ator nunca possuirá uma técnica permanente "fechada", pois cada degrau do seu autoescrutínio, a cada definição, a cada excesso, a cada derrubada de barreiras escondidas, encontrava ele novos problemas técnicos em um nível mais alto. [...] Mas o fator decisivo nesse processo é a técnica de penetração psíquica do ator. (GROTOWSKI, 1971, p. 22)

O treinamento pautado pelo conceito de via negativa não constituía um ponto de chegada, mas um caminho que poderia levar o ator a se investigar, afinal "não é necessário saber como fazer, mas não hesitar frente ao desafio". (GROTOWSKI, 1974 In FLASZEN e POLLASTRELLI 2007, p. 201. Grifo nosso) Neste entendimento, o mais importante para a criação atoral seria o modo como nos relacionamos com os exercícios em um treinamento ou procedimento cênico.

Ludwik Flaszen, em entrevista pública realizada no Brasil em 2009, mencionou que a via negativa - "a pesquisa do essencial pela eliminação"9 - teria surgido, na trajetória de Grotowski, inspirada pelo método de denomi-

\footnotetext{
8 "Autopenetração" é um conceito forjado por Jerzy Grotowski que, segundo Motta Lima (2012), está ligado à investigação dos processos psíquicos do ator: "[...] buscava-se acessar ou penetrar as zonas psíquicas mais desconhecidas, íntimas, reclusas e, sobretudo, dolorosas e bloqueadas de cada ator. Buscava-se o 'núcleo mais secreto da nossa personalidade'". (MOTTA LIMA, 2012, p. 110)

9 Fragmento da Entrevista Pública de Ludwik Flaszen, no Seminário Internacional Grotowski 2009: uma vida maior do que o mito, com curadoria da Professora Doutora Tatiana Motta Lima. Ocorrida em 02 de dezembro de 2009. Arquivos pessoais de Tatiana Motta Lima.
} 
nação negativa de Deus da teologia mística cristã, cuja origem remonta ao Pseudo Dionísio Areopagita ${ }^{10}$. Personagem da mística cristã do século VI, Pseudo Dionísio Areopagita legou um conjunto de obras intitulada Corpus Dionysiacum, composto por quatro tratados, a saber: Da Hierarquia Celeste; Da Hierarquia Eclesiástica, Dos Nomes Divinos e Da Teologia Mística, acrescida de dez cartas. Apesar de sua origem duvidosa ${ }^{11}$, estas obras foram fundamentais para a formação do cristianismo medieval tanto no que diz respeito à sua prática litúrgica, quanto ao pensamento teológico.

Uma das ideias mais importantes contidas no Corpus Dionysiacum é a ideia de que Deus, "[...] é um mistério transcendente de todo ser"12 e, por isso, ele não pode ser compreendido a partir das coisas existentes. É uma tarefa difícil para o homem, através de sua inteligência, nomear Deus, já que este transcenderia todo o conhecimento. Por conta disso, seria necessária uma metodologia contrária à da afirmação:

Afirmar, para o Pseudo Dionísio Areopagita, é partir do princípio das coisas $\mathrm{e}$ ir acrescentando-lhes afirmações, até chegar aos extremos, à totalidade do que se pode falar sobre esse princípio. Já com a negação, se dá ao contrário: a partir dos extremos, vãose retirando as afirmações até chegar ao cume do desconhecido, onde não há palavras nem reflexão. Elimina-se,

10 Dionísio, o Areopagita, é um nome que aparece no Novo Testamento, no livro dos Atos dos Apóstolos, na passagem que fala sobre a ida do apóstolo Paulo à Grécia. A passagem relata o discurso do apóstolo no Areópago Grego e a falta de adesão à doutrina cristã dos ouvintes. A passagem relata que algumas poucas pessoas resolveram seguir o apóstolo e, entre elas, estava Dionísio, o Areopagita. Por isso, o autor dos documentos encontrados no século VI ficou conhecido como Pseudo Dionísio Areopagita. (CASTRO, 2009, p.15)

$11 \mathrm{Na}$ época em que surgiu, alguns teólogos questionaram a validade dos documentos por não se saber exatamente qual era sua origem.

12 Trecho do tratado Da Hierarquia Celeste apud CASTRO, 2009, p.47. assim, tudo o que envolve o princípio das coisas - e impede o seu conhecimento pelos homens, para chegar à união com o incognoscível. (CASTRO, 2009, p. 50)

Para que o homem possa experimentar o divino, deve retirar toda afirmação sobre Ele (Deus) e aceitar esta experiência como um "não saber" ligado à transcendência, pois o verdadeiro conhecimento do que é divino só pode chegar ao homem através da aceitação do "não saber", pela via da negação:

Ele (Deus) ultrapassa todo o ser e conhecer. Seu ser está acima de todo ser. A mente não alcança conhecê-lo. Negando a ele, pois, existência como a nossa, negando que nosso conhecimento o conhece, esse perfeito não saber, no melhor sentido, é conhecer aquele que está acima de quanto se possa conhecer. (AREOPAGITA apud CASTRO, 2009, p. 50)

Apesar de não ser possível encontrar em nenhum texto do próprio Grotowski uma referência ${ }^{13}$ direta ao Pseudo Dionísio Areopagita, podemos reconhecer semelhanças entre as duas propostas de uso da via negativa e da importância dada à questão do "não saber". No relato que fez do espetáculo Apocalypsis

13 Pseudo Dionísio Areopagita é considerado por estudiosos como o "príncipe dos místicos cristãos" e que, por isso, influenciou diversos místicos e filósofos da teologia. Entre os nomes mais importantes estão o Mestre Eckhart (12601328) e San Juan de La Cruz (1542-1591). Estas duas figuras aprofundaram as ideias do Areopagita, sobretudo no que diz respeito à impossibilidade de nomeação do divino. Apesar de Grotowski não evidenciar uma ligação direta com o Areopagita, é possível reconhecer sua conexão com as figuras de Mestre Eckhart e San Juan de La Cruz. Grotowski cita, em sua última conferência do Collège de France (1998), a proposição do Mestre Eckhart sobre o homem interior, que é também um fragmento presente em seu texto O Performer (1989). Além disso, os escritos de San Juan de La Cruz foram utilizados por Grotowski no processo de construção do espetáculo O Príncipe Constante. É possível, portanto, confirmar, através desta relação, a afirmação de Flaszen de que o Pseudo Dionísio Areopagita teria influenciado Grotowski. 
cum Figuris $^{14}$ (1969) por exemplo, Grotowski afirma que este foi um processo pautado pela recusa daquilo que já sabiam, das fórmulas e modos de fazer que eles, enquanto companhia, já tinham construído para si, sendo, por isso, o processo de criação que durou mais tempo no trabalho do Teatro Laboratório (três anos no total).

Neste processo, a busca do "não saber", por aquilo que não era conhecido e familiar, estava ligada à perseguição de algo que fosse fértil e não estéril. Seria como preparar um terreno para a criação e, neste terreno, o "fertilizante" seria o "não saber". Grotowski (1984 apud FLASZEN e POLLASTRELLI, 2007, p.181) afirma que, nos três anos de processo que se seguiram, ele, juntamente com os atores, passou por diversos abandonos: abandono do texto inicial, abandono de estruturas, abandono de metodologias de trabalho anterior, etc. Sendo sempre motivados por aquilo que ele denominou como "a coragem da renúncia".

Podemos perceber aqui uma semelhança entre a proposta do Pseudo Dionísio Areopagita e a de Grotowski, em que, para o primeiro, a aceitação da condição humana de não conhecer o divino seria a chave para a real transcendência; enquanto que, para o segundo, a busca do "não saber", pelo artista, seria a condição sine qua non para a criação. $\mathrm{E}$, tanto para um como para o outro, o acesso se daria através da via da negação, ou via negativa.

14 Este espetáculo foi o último dirigido por Jerzy Grotowski. Teve como codiretor: Ryszard Cieślak e como assistente de direção: Stanisław Scierski. Elenco: Antoni Jahołkowski, Ryszard, Zygmunt Molik, Zbigniew Cynkutis, Elizabeth Albahaca / Rena Mirecka, Stanisław Scierski. Teve sua estreia oficial em 1969 e foi apresentado até 1980.
O treinamento

negativo no Studio Stanislavski

Com base no exposto, a partir de agora, iremos nos debruçar sobre a apropriação da via negativa pela companhia teatral carioca Studio Stanislavski. Criada em 1991 por Celina Sodré ${ }^{15}$, esta companhia investiga o trabalho do ator tendo como base as perspectivas de Jerzy Grotowski e Constantin Stanislavski. Ao longo destes 25 anos de existência, o Studio Stanislavski tem concebido e realizado projetos que visam o aprofundamento da pesquisa sobre a arte do ator. Alguns exemplos destas ações são: Polo Sul-Americano do Ator Contemporâneo ${ }^{16}$ (1998 a 2000), a fundação do Instituto do Ator (2008) e o Grupão Grotowski ${ }^{17}$ (2008 a 2016). Na edição de maio de 1999 do Polo Sul-Americano do Ator Contemporâneo, um dos artistas participantes do encontro, o iraniano Massoud Saidpour ${ }^{18}$, ministrou um treina

\footnotetext{
15 A trajetória de Celina Sodré foi marcada por diversos eventos em que teve contato com Grotowski e sua obra. Dois exemplos, destacados por Sodré como determinantes, foram: assistir, em 1988, ao trabalho do Workcenter (que, na época, estava abrindo as portas a testemunhas) e a participação, em 1989, no Objective Drama Program, coordenado por Grotowski em Irvine, na Califórnia. (Estas informações foram retiradas de arquivos pessoais cedidos por Sodré).
}

16 Encontro composto por debates, sessões de cinema e workshops sobre a arte do ator com artistas brasileiros e estrangeiros.

17 É um grupo de estudos, aberto e gratuito, que acontece uma vez por semana no Instituto do Ator. O grupo é coordenado por Celina Sodré e tem como norte do trabalho a leitura e discussão dos textos de Grotowski, principalmente as últimas conferências do Collège de France, que são objeto da tese de doutorado de Sodré (2014), além de outros textos relacionados à obra do polonês.

18 Massoud Saidpour é diretor de Performing Arts do Cleveland Museum of Art (EUA). Saidpour foi colaborador do mestre de teatro polonês Jerzy Grotowski, ao longo de oito anos, na Universidade da Califórnia, em Irvine. Desde o ano de 1999, conduziu oficinas e dirigiu residências de teatro no Brasil. 
mento físico ${ }^{19}$, inspirado no treinamento desenvolvido por Grotowski no Teatro Laboratório.

Analisaremos, a seguir, como se deu o trabalho atoral com este treinamento e as questões decorrentes, ocorridas em três fases ${ }^{20}$ distintas do Studio Stanislavski. A primeira fase teve início em 1999, com a chegada de Saidpour ao Brasil e a transmissão da estrutura do treinamento. Deste primeiro momento, foram entrevistados os atores ${ }^{21}$ : Dinah Cesa$\mathrm{re}^{22}$, Joana Levi ${ }^{23}$ e Bruce Gomlevsky ${ }^{24}$. A segunda fase incide no ano de 2008, quando a sede da companhia foi transferida para o bair-

19 Dinah Cesare (2010) nomeia esta estrutura como treinamento físico, seguindo a denominação de Grotowski para a relação dos exercícios criados a partir das posturas do Hatha Yoga. A estrutura deste treinamento é fixa e composta por alguns elementos como: colocar-se no espaço; andar; $1^{\text {a }}$ corrida; dança pessoal; exercícios plásticos; transição; primeiro exercício individual; transição; segundo exercício individual; transição; exercícios com os pés; transição; terceiro exercício individual; transição; quarto exercício individual; transição; segunda corrida com rolamentos acrobáticos; transição; quinto exercício individual; transição; sexto exercício individual; transição; rolamentos finais elaborados com asanas e repouso.

20 Importante ressaltar que, nos seus 25 anos de existência, o Studio Stanislavski teve diversas configurações. A escolha do tipo de treinamento a ser realizado sempre foi facultada aos atores, pela diretora Celina Sodré, de acordo com suas afinidades, mas a via negativa se manteve como ética norteadora do trabalho.

21 As entrevistas com os atores e atrizes Dinah Cesare, Joana Levi, Bruce Gomlevsky, Douglas Resende, Evelin Reginaldo e Mariana Rosa figuram na dissertação de mestrado "Em busca da autonomia criativa - uma investigação da relação entre teatro e pedagogia com base no conceito de via negativa". (GOMES, PPGAC/UNIRIO, 2016)

22 Dinah de Oliveira (Dinah Cesare) - Doutoranda em Artes Visuais na EBA/UFRJ. Coordenadora Artística do Instituto do Ator. Atriz da Companhia Studio Stanislavski e professora de treinamento físico para atores.

23 Joana Levi - Atriz, diretora e produtora teatral. Em 1994, foi para Itália onde acompanhou processos de criação da Fondazione Pontedera Teatro, realizou residência artística com a atriz e diretora Silvia Pasello e participou de sessões de trabaIho no Workcenter of Jerzy Grotowski. Trabalhou com Celina Sodré, como atriz e assistente de direção, de 1995 a 1999.

24 Bruce Gomlevsky - Ator, produtor e diretor. No teatro, integrou, durante três anos, a Companhia de Ópera Seca, sob a direção de Gerald Thomas. Atuou em mais de vinte espetáculos teatrais. Foi indicado ao prêmio de Melhor Ator, no III Prêmio Cultura Inglesa de Teatro. ro da Lapa, no centro do Rio de Janeiro, com a criação do Instituto do Ator. Deste período, foram entrevistados os atores:

Douglas Resende ${ }^{25}$ e Evelin Reginaldo ${ }^{26}$. A última fase data de 2014, quando foi criado o grupo Os Novos ${ }^{27}$, no Instituto do Ator ${ }^{28}$. Desta fase, foi entrevistada a atriz Mariana Rosa ${ }^{29}$.

Por meio destas entrevistas, foram investigadas algumas questões apresentadas por Grotowski como elementos primordiais ao treinamento. É interessante notar como as percepções dos atores são distintas e como esta diferença está relacionada com o tempo de prática com o treinamento. Este fato revela a importância do fator tempo no trabalho de pesquisa com o treinamento físico e o quanto a estrutura necessita estar aberta a constantes transformações.

25 Douglas Resende - Ator e produtor cultural. Mestrando em Artes Cênicas pela UNIRIO. Coordenador do espaço cultural Instituto do Ator. Ingressou no Studio Stanislavski em 2008, onde participou como ator das peças Fantasmas de Guerra e Paz (2012) e TransTchecov (2009).

26 Evelin Reginaldo - Possui Mestrado em Estudos Contemporâneos das Artes pela UFF, com foco sobre a pesquisa no trabalho do ator e principalmente no termo Corpo-memória, desenvolvido por Jerzy Grotowski. Integra o Studio Stanislavski desde 2008, onde participou de diversas produções.

27 O grupo Os Novos foi criado no Instituto do Ator em 2014, a partir da entrada de novos sócios no espaço. O grupo realizou, em 2015, a sua I Mostra de Cenas Curtas. São componentes de Os Novos: Ana Cristina, Amanda Brambilla, Aurea Sepulveda, Bruna Felix, Carolina Exaltação, Conrado Nilo, Dandara Vital, Danielli Cristine, Jony Jarp, Jorran Souza, Ketlen Cajueiro, Lucia Chequer Houaiss, Mariana Rosa, Paulo Maia e Ricardo Loureiro.

28 O Instituto do Ator é um Instituto de pesquisa da arte do ator que tem como sede um prédio na Rua da Lapa, 243, no bairro da Lapa, na cidade do Rio de Janeiro. Nele, são desenvolvidas pesquisas em torno da arte teatral e workshops para sócios e não sócios do espaço. O Instituto é também a sede do Studio Stanislavski.

29 Mariana Rosa - Atriz e fisioterapeuta, associou-se ao Instituto do Ator, onde desenvolve pesquisa sobre as possibilidades do corpo, conduzindo o training e trabalhando como atriz. Participou do II Festival Ratos de Palco, sendo indicada como melhor esquete. 


\section{Não saber, risco e limite}

Quando Grotowski propõe que a prática do treinamento seja pautada pela via negativa, 0 que deve ser trabalhado pelo ator é algo que ele não sabe fazer, em busca da "eliminação dos bloqueios". (GROTOWSKI, 1968 In FLASZEN e POLLASTRELLI, 2007, p. 106) Nesta perspectiva, o ator se coloca em uma situação de risco tanto no treinamento quanto na criação, o que permite a expansão de seus limites. No treinamento físico, notamos que há uma lei específica para trabalhar esta questão: a lei de se colocar no limite. Apesar de este princípio nortear toda a estrutura, ele se faz presente em alguns elementos de forma mais determinante, como nos exercícios individuais ${ }^{30}$, na corrida com rolamentos e no rolamento com as asanas $^{31}$.

Estas questões do risco e do contato com o desconhecido podem ser identificadas nas entrevistas realizadas com os atores do Studio de forma sistemática, sob várias perspectivas. Dinah Cesare (2016), por exemplo, relata, em sua entrevista, a maneira como a questão do desconhecido foi colocada, para ela e suas companheiras, logo no início do contato com o treinamento físico, levando a um "desfazimento" cotidiano no ato de treinar:

Você vai todo dia fazer algo que você não sabe?! E não é só você que não sabe. Nós três não sabíamos: eu, Paula e Joana. Não saber fazer, é da es-

30 " [...] microestruturas de movimentos em sequência, com início, meio e fim. Devem ser realizados em diferentes direções e tempo-ritmo". (CESARE, 2010, p.29)

31 As asanas (posturas do Hatha Yoga), escolhidas para o treinamento, são: "as de três pontas (cabeça e mãos tocam o chão), a vela (parte posterior da cabeça, nuca e trapézio, ombros, braços e cotovelos formam a base no chão) e o escorpião (postura unilateral, cuja base é formada por um dos ombros, o pescoço, um dos braços e a mão)". (CESARE, 2010, p. 30) trutura que você não sabe. Então, para mim, isso é um desfazimento, é um negativo no sentido daquilo que você sabe fazer, daquilo que você quer saber fazer e dessa via cultural. Então, é (eu acho que tinha isso no Grotowski, eu entendia muito assim) experimentar certas posturas, por exemplo, as de yoga, eram menos para mim do que é a conexão com esse lugar hindu da formalização, mas era conexão com esse lugar hindu daquilo que não se sabe, porque eu não sei do yoga, não sei mesmo e ao mesmo tempo então tem que construir outro entendimento.

Joana Levi (2016) considera que o contato direto com o "não saber", principalmente com elementos da estrutura do treinamento que estimulam o risco físico, permitem a ampliação da autoconfiança:

O treinamento me deu uma confiança no meu corpo, porque eu tenho um corpo que é potente, que pode mais do que acho que ele pode. [...] A gente pode fazer o treinamento de uma forma dogmática, tem que passar do limite, aí você fica ali se autoflagelando, ou você saca o que é precioso nessa regra, [...] sai do controle e percebe que você pode mais, que tem sempre um campo desconhecido. Porque, às vezes, o campo desconhecido é na resistência física e, outras vezes, é na imaginação, nas associações, na autoria, na busca por temas. Afinal, onde é que está o teu limite em cada momento?

Douglas Resende (2016) leva a reflexão que faz Levi um pouco além, quando relaciona a superação dos medos, que a situação de risco no treinamento físico porta, com a experimentação da sensação de prazer e liberdade:

[...] acho que você fica bem treinado, digamos assim, a fazer essas situações de risco, que, na verdade, fica muito natural para você pegar uma coisa e encarar [...] Sempre foi um momento de muito prazer, dessa sen- 
sação de liberdade [...] você fica destemido [...] O training ${ }^{32}$ te dá isso. $\mathrm{Na}$ verdade, você não fica destemido ali, você fica destemido na vida.

É importante reconhecer, no entanto, que o risco e o desconhecido no treinamento físico devem ser elementos em constante transformação. No momento em que algum exercício, sobretudo os exercícios individuais, torna-se facilmente realizável dentro da estrutura, ela deve ser renovada. Evelin Reginaldo (2016) comenta esta necessidade de renovação:

Eu acho que eu precisava renovar o training, como se já tivesse fácil para mim, precisava criar um novo training, criar coisas difíceis dentro daquela estrutura. [...] Naquele momento, eu achava que o training não servia para mim, mas não era isso. Hoje em dia, eu acho o training superimportante, mas não aquela estrutura exatamente.

No trabalho sobre o desconhecido, o ator não coleciona técnicas, como afirma Grotowski (1968 In FLASZEN e POLLASTRELLI, 2007, p. 106), mas elimina os bloqueios. Nesse sentido, Mariana Rosa (2016) afirma o motivo pelo qual o treinamento físico foi uma escolha em suas pesquisas como atriz:

Eu gosto dessa ideia do não ensinamento, porque você vai para uma escola, aprende os códigos da escola, mas isso é uma forma de não trabalhar a liberdade. Você vai aprender uma técnica, mas o training é você dentro daquela estrutura, aprender a desbloquear, porque eu acho que qualquer estrutura limita você em uma forma, causa ainda mais bloqueio.

\section{Trabalho sobre si mesmo \\ e corpo-memória}

\section{Grotowski (FLASZEN e POLLASTRELLI,} 2007) afirma que o objetivo deste trabalho seria permitir ao ator uma "maturação", na direção de conduzi-lo a um completo "desnudarse, por um revelar a própria intimidade". Este trabalho teria dois objetivos: não permitir que os conflitos e bloqueios individuais impeçam a criação e permitir que o ator acesse suas memórias e associações pessoais como elementos potentes para o seu processo criativo.

Grotowski (1971, p. 172) afirma que as associações emergem do corpo, traduzidas em reações físicas: "foi a nossa pele que não esqueceu; nossos olhos que não esqueceram". Sendo assim, o corpo não traria consigo uma memória, mas seria a própria memória, tal qual um corpo-memória. O confronto sobre o risco no trabalho do ator sobre si mesmo permite a liberação deste corpo-memória para a criação. Esta percepção dos desbloqueios daquilo que Grotowski chama de corpo-memória pode se dar através da percepção da integração entre o físico e o psíquico, como lembra Evelin Reginaldo (2016):

[...] algumas coisas que eu estava trabalhando no corpo acabaram repercutindo mais psiquicamente do que fisicamente, não era óbvio fisicamente. Mas psiquicamente, sim. [...] Por exemplo, eu tinha uma tensão na mão, [...] eu nunca conseguia entender porque a Dinah fazia uma coisa com a minha mão. Para mim era porque eu estava fazendo o exercício plástico errado ou estava tensionando a mão. $\mathrm{Na}$ verdade, minha mão é um reflexo do jeito que eu sou, só isso.

Evelin Reginaldo (2016) conta inclusive que, por vezes, descobertas de associações e ima-

32 Nas entrevistas, os atores se referem à estrutura do treinamento físico, proposto por Saidpour, como training. O uso da palavra training como um termo recorrente na prática da companhia se dá por respeito a uma escolha do próprio Grotowski que preferia o uso do termo em inglês. 
gens visualizadas durante a execução do treinamento físico foram incorporadas às suas criações como atriz:

Que para mim o training é mais do que o training só de exercício [...] muitas vezes, eu criei a partir de algumas estruturas que vieram por causa do training. [...] Vou começar com a do peixe, a do Van $\mathrm{Gogh}^{33}$. A imagem do peixe veio na hora que eu estava fazendo o training, depois eu estruturei aquilo, não é que a estrutura tenha vindo, enquanto eu estava fazendo o training, mas a imagem surgiu durante o training.

\section{Criação artística} e prática do treinamento: precisão e espontaneidade, contato e presença

Segundo Grotowski (2001), ao ator é sempre necessário em sua criação compor uma partitura de ações físicas, baseadas no princípio da organização e também no fluir dos impulsos. Isto, no treinamento físico, como relembra Joana Levi (2016), pode estar ligado a experimentações de novos modos de fazer a estrutura de acordo com fluxo das sensações, sem negá-las ou julgá-las:

Como é que eu vou impedir que nada me trave no final das contas? Porque eu posso estar com raiva, Grotowski é o primeiro a dizer: a gente não comanda as emoções. Se a gente não comanda as emoções para usá-las no sentido da ação, como é que eu vou comandá-las para não sentir? Não dá para fazer. Porque até hoje, com todas as apropriações que eu fiz, o que vale mais para mim é esse lugar de pesquisa sobre meu próprio estado no momento. Eu lembro um dia que, estava

33 Evelin Reginaldo se refere ao espetáculo Dois Jogos e Sete Jogadores (2010), dirigido por Celina Sodré. Um dos textos que compunham o espetáculo eram trechos do livro Cartas a Theo, no qual estão publicadas cartas de Van Gogh a seu irmão. com a Dinah e com a Paula... Não sei por que, eu me irritei, e era a hora de dar as cambalhotas. Eu dei a cambaIhota com a raiva e percebi que tinha essa possibilidade. Foi engraçado porque foi algo muito banal, que me ensinou muito.

É nesta relação entre a precisão da forma e o fluir dos impulsos que ressoa a afirmação de Grotowski sobre o objetivo da formação do ator pelo treinamento negativo: "a liberdade do intervalo de tempo entre o impulso interior e a reação externa em um modo tal que o impulso é já uma reação externa". (GROTOWSKI, 1968, In FLASZEN e POLLASTRELLI, p. 105) E a diminuição deste intervalo pode revelar ao ator sua própria corporeidade, como comenta Dinah Cesare (2016):

A gente fala 'meu corpo', a gente não é nada fora do corpo. Não tem uma coisa pairando aqui, a gente é o corpo. [...] E você não visualiza fora de você, porque é isso, a gente visualiza, a gente bota a mão na cabeça, porque quer ter uma hierarquia para cabeça, é o cérebro. A gente leva a mão à cabeça, mas [...] quando você leva a mão, tem uma série de musculaturas do corpo sendo investidas. Então é isso, não é fora do teu corpo essa inteligência por mais que a gente diga: "aí na cabeça".

Grotowski (2001) afirma que cada ação física partiria de um movimento subcutâneo que seria o impulso, mas que este só existiria na relação com um parceiro. Este parceiro, não necessariamente o de cena, é a conexão com algo externo. Como a ligação com o externo é determinante para o impulso e este, por sua vez, é crucial na criação do ator, o contato com o externo é fundamental no treinamento negativo.

Podemos constatar esta determinância se analisarmos algumas leis colocadas no treina- 
mento físico: ver e enxergar; ouvir e escutar; equilibrar o espaço; os exercícios devem ser realizados em lugares distintos e não podem levar o ator a se machucar e nem machucar outro participante. Se observarmos atentamente, estas leis colocam a realização da estrutura em contato direto com os elementos externos. Em respeito a estas leis, o ator deve se relacionar com o espaço concreto da sala em que trabaIha, com os parceiros e com qualquer possibilidade de interferência que possa surgir. Estar aberto a esta conexão significa ser afetado por estes elementos, deixando fluir o impulso. Douglas Resende (2016) comenta, por exemplo, esta ligação com os elementos externos a partir do elemento espaço e sua influência no seu trabalho artístico:

Em relação à consciência do espaço, eu tinha uma facilidade de saber onde estavam os objetos, onde estavam as pessoas no espaço em relação a mim, me mover pelo espaço com muita facilidade, equilibrar o espaço com muita naturalidade, é muito fácil. Como, por exemplo, andar na rua, até hoje quando eu ando na rua, eu posso estar distraído com o celular na minha mão e se vem uma pessoa na minha direção, naturalmente meu corpo desvia da pessoa. Então, o treinamento me ajudava nisso.

Na percepção dos elementos externos, coloca-se a questão da necessidade do ator estar presente e atento ao que se passa, o que Grotowski (2001) denominou como "hic et nunc", ou seja, "aqui e agora". Esta necessidade percorre tanto a criação quanto o treinamento. No treinamento físico, o aqui e agora pode ser verificado no depoimento de Evelin Reginaldo (2016), quando identifica como no "training isso fica claro, obviamente, se você está presente ou não, porque se você não está presente ou você se machuca, ou acontece al- guma coisa ou o training foi ruim".

$\mathrm{Na}$ criação, a percepção da presença do ator é mais subjetiva, porém, igualmente necessária à construção daquilo que Grotowski (1968 In FLASZEN E POLLASTRELLI, 2007) definiu como a essência da arte teatral - o encontro entre o ator e o público. Sobre isso, Bruce Gomlevski (2016) exemplifica: “não, não é você conseguir, porque o que é importante é a tua presença em cena. Isso é o cerne da questão para mim [...] Teatro é com o público. Não tem um fim em si mesmo, sabe, não pode ter um fim em si mesmo".

\section{Conclusão}

Ao analisar as percepções dos atores do Studio, notamos que através do treinamento físico foi possível eles experienciarem as proposições de Grotowski sobre o ofício atoral. É interessante perceber, no entanto, que esta possibilidade de experimentação está atrelada, de forma mais contundente, aos princípios que regem a sua estrutura do que aos elementos concretos que a compõem. Tal fato nos permite concluir que considerar uma estrutura como um treinamento negativo requer uma vinculação com o princípio da via negativa.

Grotowski (1997 apud SODRÉ, 2014) afirma, por exemplo, que a escolha de utilizar posturas do yoga como base para o treinamento do Teatro Laboratório apenas se deveu ao fato deste ter sido o material mais acessível a ele na época. O que realmente importa, na escoIha deste ou de outro exercício para compor um treinamento, é o modo como um ator se relaciona com ele e não o exercício em si. A abordagem negativa do treinamento tem como principal finalidade a "percepção de si", o que 
se torna evidente pelas entrevistas aqui analisadas.

É possível averiguar esta questão, por exemplo, em relatos como o da atriz Joana Levi, quando ela deixa fluir a sua emoção durante a execução de um exercício ou de Evelin Reginaldo, quando ela percebe a relação da tensão que escapa em sua mão. Ou ainda, no depoimento de Mariana Rosa, quando ela comenta ter escolhido esta prática de treinamento por causa da ideia do não ensinamento. Neste sentido, o treinamento físico praticado no Studio Stanislavski, no Rio de Janeiro, pode afinar a autopercepção do artista cênico, contribuindo para a elaboração de um processo autônomo, aqui considerado, como um treinamento negativo.

Referências

BONFITTO, Matteo. O ator compositor. São Paulo: Perspectiva, 2002.

BROOK, Peter. Avec Grotowski. Tradução: SODRÉ, Celina; ANDRADE, Raphael. Ed: Teatro Caleidoscópio, 2011.

CASTRO, R.C.G., Negatividade e Participação: A influência do Pseudo Dionísio Areopagita em Tomás de Aquino - Teologia, Filosofia e Educação. Tese apresentada na Faculdade de Educação da Universidade de São Paulo - USP, São Paulo, 2009.

CESARE, Dinah. Pensamento Material: O Training como Linguagem. Dissertação de Mestrado. Programa de Pós-graduação em Artes Cênicas, UNIRIO, 2010.
FLASZEN, Ludwik, POLASTRELI, Carla. O Teatro Laboratório de Jerzy Grotowski 1959 a 1961. Tradução: RAULINO, Berenice. São Paulo: Perspectiva, 2007.

GOMES, Carolina Almeida. Em busca da autonomia criativa - uma investigação da relação entre teatro e pedagogia com base no conceito de via negativa. Dissertação de Mestrado. Rio de Janeiro, PPGAC/UNIRIO, 2016.

GROTOWSKI, Jerzy. Em busca de um teatro pobre. Tradução: CONRADO, Aldomar. Rio de Janeiro: Civilização Brasileira, 1971.

O Príncipe Constante de Ryszard Cieslak. In BANU, GEORGE. Ryszard Cieslak - Ator Símbolo dos Anos Sessenta. Tradução: MALLET, Roberto. 2015.

Resposta a Stanislavski. Tradução: GOMES, Ricardo. In: Revista Folhetim, Rio de Janeiro, 2001 [1980].

MOTTA LIMA, Tatiana. Palavras Praticadas: 0 percurso Artístico de Jerzy Grotowski-1959 a 1974. São Paulo: Perspectiva, 2012.

RUFFINI, Franco. Stanislavski e o teatro laboratório. Revista da FUNDARTE. Montenegro, Fundarte, Vol. IV, 2004.

SODRÉ, Celina. Jerzy Grotowski: artesão dos comportamentos humanos metacotidianos. Tese de Doutorado. Rio de Janeiro, PPGAC/ UNIRIO, 2014.

Recebido: 01/12/2016 Aprovado: 23/12/2016 